\title{
BMJ Open Clustering of malignant pleural mesothelioma in asbestos factories: a subgroup analysis in a 29-year follow- up study to identify high-risk industries in Taiwan
}

\author{
Lukas Jyuhn-Hsiarn Lee, ${ }^{1,2,3,4}$ Cheng-Kuan Lin, ${ }^{5}$ Chih-Hong Pan, ${ }^{6,7}$ Yawen Cheng, ${ }^{8}$ \\ Yu-Yin Chang, ${ }^{1}$ Saou-Hsing Liou, ${ }^{1}$ Jung-Der Wang ${ }^{9,10}$
}

To cite: Lee LJ-H, Lin C-K, Pan $\mathrm{C}-\mathrm{H}$, et al. Clustering of malignant pleural mesothelioma in asbestos factories: a subgroup analysis in a 29-year follow-up study to identify high-risk industries in Taiwan. BMJ Open 2018;8:e021063. doi:10.1136/ bmjopen-2017-021063

- Prepublication history and additional material for this paper are available online. To view these files, please visit the journal online (http://dx.doi org/10.1136/bmjopen-2017021063).

Received 12 December 2017 Revised 14 September 2018 Accepted 16 October 2018

Check for updates

(C) Author(s) (or their employer(s)) 2018. Re-use permitted under CC BY-NC. No commercial re-use. See rights and permissions. Published by BMJ.

For numbered affiliations see end of article.

Correspondence to Dr Jung-Der Wang; jdwang121@gmail.com

\section{ABSTRACT}

Objective Exposure to asbestos is the major cause for malignant pleural mesothelioma (MPM), but the causal link of individual cases is difficult to establish for lack of exposure information and long disease latency.

Methods We established a retrospective cohort of workers employed in asbestos industries during the period of 1950-1989 and the occurrence of MPM during the period of 1980-2009 was examined with the Taiwan Cancer Registry. Estimated rate ratios (eRRs) were computed for each factory where any case of MPM was diagnosed by assuming Poisson distribution with a minimal latency of 20 years.

Results A total of 18 MPM (17 males, 1 female) in eight factories were found. The incidence rate of MPM for the eight factories was 18.0 per million, ranging from 6.2 per million (military factory) to 268.2 per million (asbestos cement). We observed significantly increased risks for MPM in asbestos cement, thermal insulation and shipbuilding industries, with eRR (genders combined) of 113.6, 87.5 and 15.8, respectively. The sensitivity analyses considering latency showed similar findings in latency $\geq 30$ years, and the shipbuilding industry presented a significant eRR given a latency $\geq 40$ years. The gender-specific eRR showed similar results in men, but high eRR of 729.6 was observed in an asbestos cement factory where a female MPM was diagnosed.

Conclusions This nationwide study in Taiwan comprehensively shows that different asbestos manufacturing processes, including asbestos cement, thermal insulation and shipbuilding industries, were at significantly increased risks for MPM. We recommend to establish a medical screening programme for workers previously exposed to asbestos to identify MPM and other asbestos-related diseases at an earlier stage.

\section{INTRODUCTION}

Asbestos is a generic term for 'fibrous silicate mineral fibres of a crystalline nature'. ${ }^{1}$ It gained worldwide usage because of its excellent heat and acid resistance, among other properties. It has been used in various
Strengths and limitations of this study

- Based on the nationwide cohort study of asbestos-related industries defined by Taiwan's Labour Insurance programme, we performed a subgroup analysis on the pattern of clustering of the 18 malignant pleural mesothelioma (MPM) cases identified in eight factories.

Our simple approach of using estimated rate ratio to identify the cluster of MPM in specific factories in Taiwan may serve as a guide for occupational health professionals to recognise more asbestos-related cancers and asbestos-related diseases (ARDs).

- Those cases of MPM could act as sentinel index of ARDs, and a discovery of one case in a factory mandates the necessity to establish a continual medical screening programme for all previous workers.

- We did not have long-term exposure data on ambient air levels of asbestos fibres, which limited our ability to develop a comprehensive job-exposure matrix and exposure scenario of each factory in this study.

industries, including construction, shipbuilding and repair, brake lining, and textiles. Worldwide consumption of asbestos reached its peak in the 1980s, before discovery of its adverse health effects led many countries to ban its use. ${ }^{2}$

Asbestos has been recognised as a human carcinogen for decades, ${ }^{3}$ but a causal link to individual cancer clusters is difficult to establish due to a lack of detailed exposure information and the long latency period associated with asbestos-related diseases (ARDs). Many ARDs have been identified since the last century, including malignant pleural mesothelioma (MPM), lung cancer, female ovarian cancer and cancer of the larynx. ${ }^{4}$ The International Agency for Research on Cancer has classified all types of asbestos as a group 
1 human carcinogen. Globally, a temporal relationship has been documented for a strong association between asbestos use in the 1960s and MPM mortality rates in the 2000s, demonstrating a mean latency period of $30-40$ years. ${ }^{5}$ Thus, many countries are expected to face MPM epidemics in the coming several decades ${ }^{6}$; current observations of increasing MPM incidence in Taiwan are in accordance with this. ${ }^{7}$

Taiwan used to be a country with asbestos mining and extensive import activities for manufacturing. Wu et al recently described the history of the asbestos use regulation process in Taiwan and the associated factors leading to the total asbestos ban in $2018 .^{8}$ The domestic asbestos mining industry started from 1937 and ended its operation in 1985. Shipbreaking began in 1949, and it grew in the 1960s. ${ }^{9}$ During 1977-1988, Taiwan became the world's largest shipbreaking nation with approximately $65 \%$ of the obsolete ships in the world, ${ }^{10}$ which declined and ended operation in $1993 .^{11}$ The majority of asbestos used in Taiwan was imported, with the amount rising significantly in the mid-1970s and peaking around 40000 tons per year in the mid-1980s and then falling significantly in the early 1990s. ${ }^{8}{ }^{12}$ Most asbestos raw materials were consumed in industrial sectors: asbestos cement, abrasion-resistant products, insulation, textiles and ships. ${ }^{13} 14$ A previous survey of occupational asbestos exposure found many workplaces exceeding the permissible exposure level. ${ }^{13} 14$ The asbestos manufacturing industries began to decrease from 1989 after enactment of Toxic Substances Control Act by the Taiwan Environmental Protection Administration (EPA), ${ }^{8}$ which banned use of asbestos in construction materials, including asbestos plate, pipe and cement, and fibre cement boards (from 2008). ${ }^{15}$ Beginning in 2018 , asbestos use is forbidden in all manufacturing in Taiwan. ${ }^{16}$ Taiwan is the 62nd country to implement a national policy on the total asbestos ban. ${ }^{817}$

The age-adjusted mortality rate of malignant mesothelioma (MM) in Taiwan was 1.14 cases per million per year ${ }^{18}$ with an increasing trend for both genders. ${ }^{7}$ The average annual incidence of MPM increased from 0.26 per million during 1980-1989, to 2.34 per million during 2005-2009. ${ }^{19}$ The trend is corroborated by 93 MPM cases diagnosed during 1977-2016 in a medical centre in Northern Taiwan. ${ }^{20}$ The health impacts from MPM were estimated to be on average 18.2 years of life lost compared with the general population, and reimbursement of lifetime healthcare expenditure by the National Health Insurance was US\$29 400 with a 3\% annual discount rate. ${ }^{21}$

We established a retrospective cohort study, using of Taiwan's Labour Insurance programme to identify those who worked in asbestos-related industries between 1950 and 1989 and followed up with the Taiwan Cancer Registry for the period 1980-2009 to identify incident cancer. Lin et al reported that male asbestos workers had an increased standardised incidence ratio (SIR 2.65, 95\% CI 1.54 to 4.25) of MPM. ${ }^{12}$ Among them, those with more than 20 working years had the highest risk $(\mathrm{SIR}=5.78)$. However, even those employed less than 1 year could be associated with an elevated risk of MPM (SIR=2.68). All male MPM cases had a median latency period of 33.2 (range 22.756.4 ) years, which could be a basis for minimum latency period of 20 years.

In this study, we examine the pattern of clustering of the 18 MPM cases identified in our cohort. Hot spot factories are identified and we estimate the rate ratios for MPM at these factories using data on the general population of Taiwan as a reference.

\section{METHODS \\ Study population}

This study is a subgroup analysis focusing on the MPM cases identified in the retrospective cohort study. ${ }^{12}$ Taiwan EPA regulates and categorises five groups of asbestos-related factories: those in the asbestos cement industry, the asbestos friction industry, the asbestos thermal insulation industry, industries using serpentine and other (not elsewhere classified). The recruitment was based on the records of labour insurance, and workers who once worked in the asbestos-related industries registered by Taiwan EPA were included as the occupational cohort. The labour insurance in Taiwan used to cover all the workers in the companies with more than five employees, and the database of labour insurance is comprehensive in recording the employment periods of each participant. Thus, the cohort captured all the workers insured by labour insurance, but did not include those uninsured, such as temporary labours, or those who have been employed in small-scale enterprises with less than five employees.

A total of 183560 workers who were ever employed in the 389 asbestos-related factories between 1 March 1950 and 31 December 2009 were included in the cohort. We obtained incident cases of cancer through linkages with the database of Taiwan Cancer Registry ${ }^{22}$ using encrypted personal identification numbers of these workers. The pathological diagnosis of MPM is coded according to cancer site of pleura (163) and morphological codes (MM, NOS (9050/3), fibrous sarcomatoid (9051/3), epithelioid (9052/3) and biphasic (9053/3)) based on the International Classification of Diseases, Oncology Version 3 (ICD-O-3) ${ }^{23}$ A total of 160640 subjects were followed from 1980 to 2009, under the assumption of a minimum latency of 20 years. Detailed information about the cohort is provided elsewhere. ${ }^{12}$

We identified 18 MPM cases (17 males and 1 female), who were clustered in eight asbestos-related factories. We performed a subgroup analysis focusing on a total of 25688 workers who worked in the eight factories. Those workers were followed up by linkage with the Taiwan Cancer Registry from 1980 to 2009.

\section{Data analysis}

The total person-years of follow-up were accumulated for each factory. We calculated the incidence rate of MPM by 
dividing the number of MPM observed in each factory by the corresponding total person-years, assuming a latency period of 20 years. Two types of incidence rates were calculated: (1) the incidence rate (combined for gender) and (2) the gender-specific incidence rate. The estimated rate ratios (eRRs) of MPM in workers at these eight factories were quantified. We defined the person-year at risk as the sum of the follow-up duration of workers who worked for more than 20 years in the corresponding factory. ${ }^{24}$ Follow-up years are calculated from the year enrolled in the factories to the year (1) incident cancer occurred, (2) censored or (3) the end of the study, whichever comes earliest. The eRRs are the incidence rates for individual factories divided by the average incidence rate of pleural cancer among the Taiwan population for the period 1980-2009, which is 1.04 per million person-years. ${ }^{25}$ The sensitivity analyses are applied with considering latency period of more than 30, 40 or 50 years. The $95 \%$ CIs of the eRRs are estimated by Byar's approximation of the Poisson method ${ }^{26}$; SAS V.9.4 was used to analyse data.

\section{Patient and public involvement}

No patients were involved in setting the research question or the outcome measures, nor were they involved in the design or implementation of the study. No patients were asked to advise on interpretation or writing up of results. There are no plans to disseminate the results of the research to study participants. We will notify the relevant government agencies in Taiwan of the high-risk industries identified in this study.

\section{RESULTS}

Table 1 summarises types of occupational exposure setting, numbers of workers and follow-up years, numbers of MPM, incidence rates, and eRRs of MPM of the individual asbestos-related factories and the factories without MPM. The eight factories with occurrence of MPM cases were factories with previous heavy asbestos exposure, while the other 381 factories constituted those with mild exposure. The average age to begin working at the factories was 22.5 years for workers with heavy exposure and 24.5 years for those with light exposure. The mean durations of employment for the former and the latter were 6.7 and 4.5 years, respectively. Years of employment varied wildly in all factories, ranging from less than 0.1 year to 42.4 years (in the shipbuilding industry), with the longest follow-up at 59.8 years in a Northern shipyard.

The incidence rate of MPM for the eight factories was 18.0 per million (95\% CI 10.6 to 28.4), ranging from 6.2 per million (military factory) to 268.2 per million (asbestos cement), which was higher than that of the general population, that is, 1.04 per million personyear for genders combined. Eleven cases of MPM were observed in the shipbuilding industry, with an incidence rate of 16.4 per million. Nine cases occurred in a Northern

Table 1 Characteristics of individual factories with occurrence of MPM with calculation of incidence rate and estimated rate ratio (eRR), and all the other factories without MPM in the asbestos-related industries of Taiwan, follow-up from 1980 to 2009 , with the latency period $\geq 20$ years

\begin{tabular}{|c|c|c|c|c|c|c|c|}
\hline $\begin{array}{l}\text { Factory serial } \\
\text { no }\end{array}$ & $\begin{array}{l}\text { Occupational } \\
\text { exposure } \\
\text { setting }\end{array}$ & $\begin{array}{l}\text { Total no of } \\
\text { workers }\end{array}$ & $\begin{array}{l}\text { No of } \\
\text { workers with } \\
\text { latency } \geq 20 \text { years }\end{array}$ & $\begin{array}{l}\text { Total person-years } \\
\text { of follow-up } \\
\text { (latency } \geq 20 \text { years) }\end{array}$ & $\begin{array}{l}\text { No of MPM } \\
\text { cases } \\
\text { (gender) }\end{array}$ & $\begin{array}{l}\text { Incidence rate, per } \\
\text { million } \\
(95 \% \mathrm{Cl})^{\star}\end{array}$ & $\begin{array}{l}\text { eRR† } \\
(95 \% \mathrm{Cl})^{*}\end{array}$ \\
\hline 1 & Shipbuilding & 11912 & 11701 & 432776 & $9(\mathrm{M})$ & 20.8 (9.5 to 39.5$)$ & 20.0 (9.1 to 38.0 ) \\
\hline 3 & Military factory & 5008 & 4671 & 161788 & $1(\mathrm{M})$ & 6.2 (0.1 to 34.4$)$ & $5.9(0.1$ to 33.1$)$ \\
\hline 4 & $\begin{array}{l}\text { Thermal } \\
\text { insulation }\end{array}$ & 1169 & 821 & 21977 & $2(\mathrm{M})$ & 91.0 (10.2 to 328.5$)$ & 87.5 (9.8 to 315.9 ) \\
\hline 6 & Petrochemical & 958 & 666 & 20566 & $1(\mathrm{M})$ & 48.6 (0.6 to 270.5 ) & 46.8 (0.6 to 260.1$)$ \\
\hline 7 & Shipbuilding & 8829 & 7827 & 238906 & $2(\mathrm{M})$ & 8.4 (0.9 to 30.2$)$ & $8.0(0.9$ to 29.1$)$ \\
\hline 8 & $\begin{array}{l}\text { Asbestos } \\
\text { cement }\end{array}$ & 136 & 124 & 3728 & $1(\mathrm{M})$ & 268.2 (3.5 to 1492.0$)$ & 257.9 (3.4 to 1434.6$)$ \\
\hline $1-8$ & All & 31210 & 28947 & 1001710 & $18(\mathrm{M}, \mathrm{F})$ & 18.0 (10.6 to 28.4 ) & 17.3 (10.2 to 27.3$)$ \\
\hline $\begin{array}{l}\text { Factories } \\
\text { without MPM }\end{array}$ & & 129430 & 80946 & 2565404 & 0 & & \\
\hline
\end{tabular}

*Byar approximation of Poisson method was applied to estimate the $95 \% \mathrm{Cl}$.

teRR=estimated incidence rate of individual factory divided by the average annual incidence rate of the general population based on Taiwan Cancer Registry in 1980-2009, which was 1.04 per million person-year for genders combined.

\#Factory no 7 had three cases of MPM, but one of the affected workers began his job in factory no 1, where he worked for 3 years; therefore, he was classified as belonging to factory no 1 .

MPM, malignant pleural mesothelioma. 
shipbuilding factory, with an eRR of 20.0 (95\% CI 9.1 to 38.0); two cases were in a Southern shipyard $(\mathrm{eRR}=8.0)$. Two cases of MPM occurred in a thermal insulation factory, contributing an incidence rate of 91 per million, which ranked the second highest. Analysis of MPM clusters in the asbestos workers' cohort revealed that those at asbestos cement, thermal insulation and shipbuilding industries were at significantly higher risk compared with the general Taiwanese population, with eRR (genders combined) of 113.6, 87.5 and 15.8, respectively. The gender-specific eRR in men showed similar results with genders combined (online supplementary table 1). Fewer person-years at risk were observed among female workers, and one case of MPM was observed in an asbestos cement factory, which contributed to a high eRR of 729.6 (95\% CI 9.5 to 4059.3 ).

Table 2 shows the sensitivity analyses considering latency of more than 20,30, 40 or 50 years. The results showed similar findings in latency $\geq 30$ years, and the shipbuilding industry presented a significant eRR given a latency $\geq 40$ years. The details of person-years and incidence rates of individual factories are presented in the online supplementary tables 2-4.

For the 18 cases of MPM, the mean age $( \pm \mathrm{SD})$ of first employment in the asbestos factories was $28.1( \pm 11.3)$ years (range 15-48), and mean work duration was 7.7 $( \pm 10.5)$ years (range $0.1-30.0)$; all of them started to enter the asbestos factories before 1982, when regulations of occupational exposure to asbestos was less restrictive, with an occupational permissible exposure limit of airborne asbestos set at 5 fibres $/ \mathrm{mL} .{ }^{27}$ All MPM cases had a latency period of more than 20 years.

Figure 1 shows the geographical distribution of all asbestos-related factories and the eight factories where MPM cases were reported. A small random error was added to the spatial coordinates of each factory to protect confidentiality. Four of the eight factories with reported MPM cases are located in Kaohsiung, a Southern industrialised harbour city, and one was at a shipbuilding factory in Keelung, a Northern harbour city. The female MPM case was found in an asbestos cement manufactory in Nantou, a rural part of central Taiwan.

\section{DISCUSSION}

To the best of our knowledge, this is the first retrospective cohort study of the nationwide asbestos-related factories in Taiwan to identify the high-risk industries. It highlights that workers employed in asbestos cement, thermal insulation, shipbuilding industries were at significantly increased risks for MPM. We identified MPM clustering in specific industries in Taiwan, in which workers would have 5.9-fold to nearly 258-fold increased risks of MPM compared with the general population. A cancer cluster is defined as the greater occurrence of a specific cancer than the expected number among a specific group of people in a defined geographical region and time period. ${ }^{28}$ Moreover, concerned individuals may contact

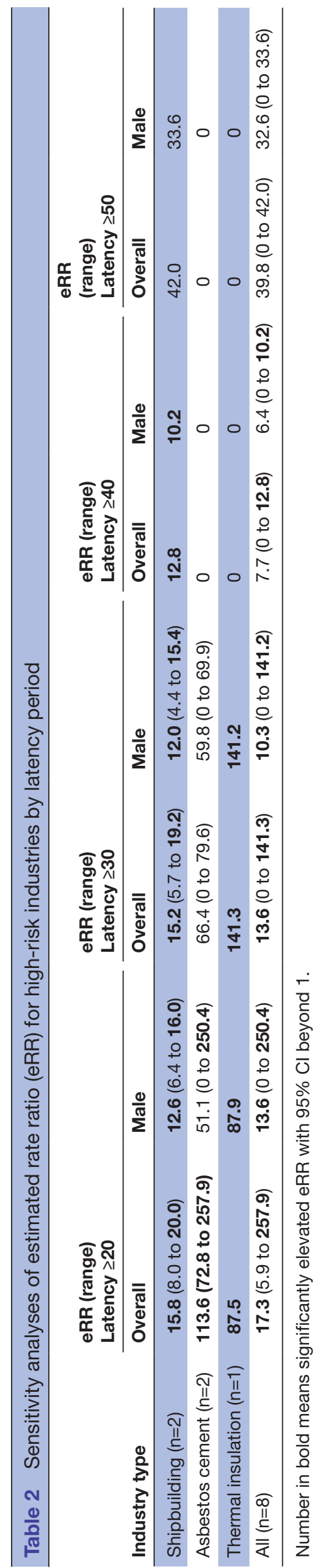




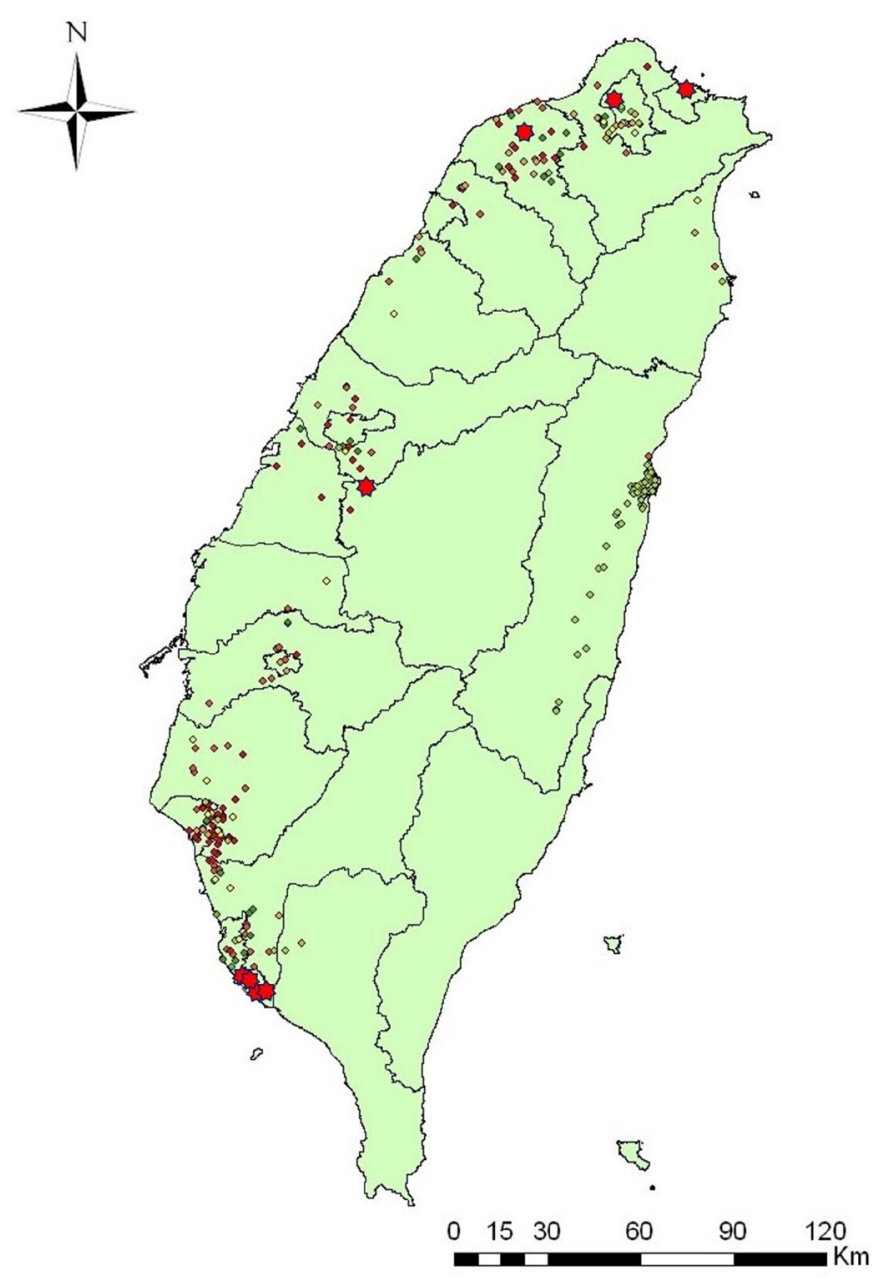

Figure 1 Geographical locations of asbestos-related factories in Taiwan with clusters of malignant pleural mesothelioma (MPM). Red stars represent the eight hot spot factories where cases of MPM were diagnosed among workers. Specific types of asbestos-related industries are shown in different colours, including red: brake lining; brown: asbestos cement; dark green: insulation; light green: serpentine stones; light orange/yellow: other.

local authorities about suspected cancer clusters, leading to in-depth investigations. Although many cases turned out not to be true clusters, thorough exposure assessments may lead to the discovery of a new carcinogen. The causal association between MPM and asbestos has been well established. ${ }^{29}$ Our findings of MPM clustered in the shipbuilding industry, ${ }^{30}$ asbestos cement manufacturing, ${ }^{29}{ }^{31}$ thermal insulation manufacturing, ${ }^{32}$ the petrochemical industry, ${ }^{33}{ }^{34}$ a sugar refinery ${ }^{3135}$ and a military factory ${ }^{36}$ corroborated positive causal links between MPM and heavy asbestos exposures in such industries worldwide.

We found nine cases of MPM in a single workplace: a shipbuilding factory, with an eRR of 20 . The relatively large number of MPM cases found in this shipbuilding factory could be explained by the size of workforce (more than 400000 person-year, contributing $45 \%$ of the person-year at risk in this study). Given the nature of low background incidence of MPM in the Taiwanese general population (1.04 per million-year, using pleural cancer as a proxy), the extremely high risk in the asbestos cement manufacturing factories ( $\mathrm{eRR}=113.6$ for genders combined, 51.1 for males, 513.8 for females; see table 1 and online supplementary table 1) may imply very high exposure of workers to airborne asbestos fibres and a poorly protected working environment. ${ }^{13} 37$ Females occupationally exposed to asbestos may be easily overlooked because of their relatively small numbers in such industries.

Asbestos exposure is estimated to account for 255000 deaths every year worldwide, making it one of the top public health issues. ${ }^{38}$ Although more than 60 countries worldwide have banned asbestos, ${ }^{17}$ some countries in Asia and the Middle East continue to consume asbestos products. ${ }^{39}$ In Taiwan, the EPA has listed asbestos as a toxic chemical since 1989 and subsequently updated related regulations eight times from 1991 to $2013 .{ }^{40}$ Asbestos fibres may be found in fire-resistant materials in construction. Thus, the risks of environmental exposure to asbestos still exist and deserve quick action to completely ban its use and application. Additionally, we must prepare to tackle the challenges of a third wave of ARDs ${ }^{41}$ that could result from exposure during demolition or replacement operations at sites with 'asbestos in place'. ${ }^{42}$

According to the guideline of labour insurance in Taiwan, ${ }^{43}$ MPM can be recognised as occupational cancer if they fulfil the criteria of (1) the diagnosis of MPM is histopathologically confirmed; (2) positive occupational history, working in the asbestos industry and (3) latency period more than 10 years. Therefore, all 18 MPM cases can be undoubtedly recognised as occupational cancer. Possibly a few cases might have concomitant exposure from environment or domestic exposure, ${ }^{44}$ such as living near the asbestos factory, or the other family member working in asbestos industries, but we have no information regarding any environmental or non-occupational exposure.

In addition to occupational exposure, environmental and paraoccupational exposure to asbestos is also a public health concern in Taiwan. We suggest that more resources should be invested in education of the general public and workers concerning the long-term health risks from asbestos exposure, and the existing asbestos in constructed buildings and environments should be labelled. ${ }^{45}$ Family members of asbestos workers could have paraoccupational or domestic exposure, for example, while washing contaminated clothing, and they must be educated to take precautionary procedures. Since environmental exposure to asbestos has induced the so-called third wave of ARDs, the potential source of asbestos in place should be identified before demolition and/or home renovation. Do-it-yourself asbestos removal is discouraged ${ }^{46}$ and it is recommended that licensed specialist firms are called in if any suspected asbestos-containing material existed in the buildings. ${ }^{47}$ To increase public awareness of the risks of asbestos and to promote prevention among the general public in Taiwan, there is 'Asbestos Hazards Information Section' webpage compiled by Taiwan EPA. ${ }^{48}$ 
This study has at least three limitations that should be kept in mind. First, we lack long-term exposure data on ambient air levels of asbestos fibres, especially in the early period. Most factories are in the other groups, which were not being able to be classified accurately based on Taiwan EPA's management system (figure 1), and heterogeneity within each group may be substantial. Thus, applying a uniform job-exposure matrix would be difficult. Second, the eRR, as an indicator to capture the relative risk of specific factories, which can reveal for gender combined and also stratified by gender. However, age adjustment was not practical because incidence rates adjusted by the direct age-adjusted method with reference to the world standardised population in the year $2000^{49}$ would fluctuate largely, which was related to relatively small number of MPM in individual factories. As the size of the exposed population is large, we believe more cases of ARDs in asbestos factories of Taiwan would be uncovered if follow-up periods could be extended. And third, underdiagnosis of MPM due to diagnosis difficulties would underestimate the risks of workers in asbestos-related industries. Using cytology from pleural effusion for diagnosis can be challenging and prone to misdiagnoses of MPM as adenocarcinoma. Immunohistochemical staining - such as calretinin, WT-1 or D2-40-can differentiate MPM from metastasis tumour from breasts, lung and/or ovarian cancer. ${ }^{50}{ }^{51}$ The relatively short median survival of MPM of about 8-14 months further reduces the opportunity for detection. During the 1970s, the pathological diagnosis of MPM was based on histology (H\&E-stained sections) and mucin histochemistry. ${ }^{52}$ At that time, the incidence of MPM was under-reported because many pathologists did not recognise the diagnosis. ${ }^{53}$ During the 1980s-1990s, Armed Force Institute of Pathology Atlas of Tumour Pathology became the major reference for pathologists in Taiwan to diagnose MPM based on morphological characteristics. ${ }^{545}$ In the 1990 s, there is a rapid growth in the application of immunohistochemistry. ${ }^{52}$ Immunohistochemical markers for diagnosing MPM have becomes widely applied since 2000 in Taiwan. ${ }^{56}$ WHO classification of tumours of the pleura published in $2004^{57}$ provides an international standard for pathologists, including in Taiwan. Such changing diagnostic criteria over time could probably underestimate the incidence of MPM, especially in early period of our study followed from 1980 to 2009. Since all cases were defined on histologically verified MPM based on ICD-O-3, it would be likely that the incidence rate ratio we estimated in this study underestimated the true relative risk.

Once a case of MPM is discovered in a factory, it is very likely just the 'tip of the iceberg,' and many more additional cases of ARDs or asbestos-related cancer would occur due to a dusty working environment even several decades ago. As increased risks of lung cancer, ${ }^{10}$ oesophageal cancer ${ }^{11}$ and stomach cancer have been reported in industries with high worker exposure to asbestos (such as shipbuilding, ship repair and ship breaking), we hypothesise that our simple approach of using eRR may serve as a guide for occupational health professionals to recognise more asbestos-related cancers. ${ }^{58}$ Because the shipbuilding and asbestos cement industries have both been in Taiwan for more than 50 years, and the asbestos textile industry has been present for more than 40 years, the incidence rates of ARDs will very likely increase in the coming decades. Current occupational health examinations in asbestos-exposed workers are limited to employees on active duty and do not take into account the extremely long latency period of ARDs. There are no health surveillance and follow-up programmes in Taiwan for those who change jobs or retire. Historically, many asbestos workers in Taiwan have been temporary labours, especially in the construction industry, or have been employed in smallscale enterprises, where occupational health is often loosely regulated and audited. Referring to the experiences of Britain, ${ }^{59}$ South Korea ${ }^{60}$ and Australia, ${ }^{61}$ we recommend setting up a national long-term surveillance system for the early detection of ARDs in Taiwan ${ }^{62}$ which is in accordance with the policy recommendations of the 18th Collegium Ramazzini statement in $2016 .{ }^{63}$ Screening programme with CT may be a potential option for the asbestos-exposed workers with sufficiently high risk of lung cancer, as suggested by the 2014 Helsinki criteria. ${ }^{64}$ A systematic review with meta-analysis published in 2014 concluded CT screening in asbestos-exposed workers as being effective in detecting asymptomatic lung cancer, with a prevalence of $1.1 \% .{ }^{65} \mathrm{~A}$ recent prospective study of 2132 Japanese asbestos-exposed workers reported that low-dose CT identified 45 cases of lung cancer $(2.3 \%)$ and 7 cases of MPM $(0.3 \%) .{ }^{66}$ However, further cost-effectiveness analysis ${ }^{67}$ on CT screening is needed for categorising high-risk groups. Moreover, workers with short-term heavy exposure must be considered, as we found MPM cases in workers with as little as 1 month of employment in an asbestos-related industry.

In summary, we have identified eight worksites with very high risks of MPM and recommended that eRR can be applied for other asbestos workers with suspected occupational cancer. In addition, a comprehensive system of early detection, long-term follow-up, compensation and prevention is indicated for asbestos workers in Taiwan.

\section{Author affiliations}

${ }^{1}$ National Institute of Environmental Health Sciences, National Health Research Institutes, Zhunan, Taiwan

${ }^{2}$ Department of Environmental and Occupational Medicine, National Taiwan University Hospital, Taipei, Taiwan

${ }^{3}$ Institute of Occupational Medicine and Industrial Hygiene, College of Public Health, National Taiwan University, Taipei, Taiwan

${ }^{4} \mathrm{Ph}$.D. Program in Environmental and Occupational Medicine, Kaohsiung Medical University, Kaohsiung, Taiwan

${ }^{5}$ Department of Environmental Health, Harvard T.H. Chan School of Public Health, Boston, Massachusetts, USA

${ }^{6}$ Institute of Labor, Occupational Safety and Health, Ministry of Labor, New Taipei City, Taiwan

${ }^{7}$ School of Public Health, National Defense Medical Center, Taipei, Taiwan ${ }^{8}$ Institute of Health Policy and Management, College of Public Health, National Taiwan University, Taipei, Taiwan

${ }^{9}$ Department of Public Health, College of Medicine, National Cheng Kung University, Tainan, Taiwan 
${ }^{10}$ Departments of Internal Medicine and Occupational and Environmental Medicine, National Cheng Kung University Hospital, Tainan, Taiwan

Acknowledgements We thank Mark Swofford at the National Health Research Institutes for his professional English editing work. We are grateful to Chien-Chou Chen at the Center for geographical information science (GIS), Academia Sinica for technical support in mapping.

Contributors $\mathrm{LJ}-\mathrm{HL}$ and J-DW contributed to the conception and design of the work. C-KL, C-HP, YC and S-HL contributed to the collection of data. C-KL, C-HP and $Y-Y C$ contributed to data preparations and definition of endpoints. $Y-Y C$ and LJ-HL carried out the data analyses. LJ-HL and C-KL drafted the paper. All authors contributed to the interpretation of data as well as critical reading and revision of the draft.

Funding This work was supported in part by the Institute of Labor, Occupational Safety and Health (grant no. IOSH-102-M3044) and the intramural projects at the National Health Research Institutes (grant no. EM-106-PP-04, EM-107-PP-04).

Competing interests None declared.

Patient consent Not required.

Ethics approval This research was approved by the Institutional Review Board of National Cheng Kung University Hospital (IRB number B-ER-102-162).

Provenance and peer review Not commissioned; externally peer reviewed.

Data sharing statement No additional data are available.

Open access This is an open access article distributed in accordance with the Creative Commons Attribution Non Commercial (CC BY-NC 4.0) license, which permits others to distribute, remix, adapt, build upon this work non-commercially, and license their derivative works on different terms, provided the original work is properly cited, appropriate credit is given, any changes made indicated, and the use is non-commercial. See: http://creativecommons.org/licenses/by-nc/4.0/.

\section{REFERENCES}

1. Smith DD. Clinical toxicology of asbestos. The health effects of asbestos: an evidence-based approach: CRC Press, 2016:27-52.

2. Frank AL, Joshi TK. The global spread of asbestos. Ann Glob Health 2014;80:257-62.

3. IARC Working Group on the Evaluation of Carcinogenic Risks to Humans. Arsenic, metals, fibres, and dusts. IARC Monogr Eval Carcinog Risks Hum 2012;100(Pt C):11-465.

4. Institute of Medicine. Asbestos: selected cancers. Washington, DC: Institute of Medicine, 2006.

5. Lin RT, Takahashi K, Karjalainen A, et al. Ecological association between asbestos-related diseases and historical asbestos consumption: an international analysis. Lancet 2007;369:844-9.

6. Neumann V, Löseke S, Nowak D, et al. Malignant pleural mesothelioma: incidence, etiology, diagnosis, treatment, and occupational health. Dtsch Arztebl Int 2013;110:319-26.

7. Lee LJ, Chang YY, Wang JD. Impact of malignant mesothelioma in Taiwan: a 27-year review of population-based cancer registry data. Lung Cancer 2010;68:16-19.

8. Wu HY, Lin RT, Wang JD, et al. Transnational Dynamics Amid Poor Regulations: Taiwan's Asbestos Ban Actions and Experiences. Int J Environ Res Public Health 2017;14.

9. Wu WT, Lu YH, Lin YJ, et al. Mortality among shipbreaking workers in Taiwan--a retrospective cohort study from 1985 to 2008. Am J Ind Med 2013;56:701-8.

10. Wu WT, Lin YJ, Shiue HS, et al. Cancer incidence of Taiwanese shipbreaking workers who have been potentially exposed to asbestos. Environ Res 2014;132:370-8.

11. Wu WT, Lin YJ, Li CY, et al. Cancer attributable to asbestos exposure in shipbreaking workers: a matched-cohort study. PLoS One 2015;10:e0133128.

12. Lin CK, Chang YY, Wang JD, et al. Increased standardised incidence ratio of malignant pleural mesothelioma in Taiwanese asbestos workers: a 29-year retrospective cohort study. Biomed Res Int 2015;2015:1-10.

13. Chang HY, Wang JD, Chang JW. Airborne asbestos concentration in asbestos-related factories in Taiwan. J Natl Public Health Assoc 1988;8:28-35.

14. Chang HY, Wang JD, Chang JW, et al. Industrial hygiene survey for asbestos-related factories in Taiwan. J Natl Public Health Assoc 1988;8:161-71.

15. Kazan-Allen L. Chronology of asbestos bans and restrictions. 2018.
16. Taiwan EPA. New environmental measures in effect. https://www. epa.gov.tw/public/Data/8219441271.pdf (accessed 7 May 2018)

17. Kazan-Allen L. Chronology of national asbestos bans. 2018 http:// www.ibasecretariat.org/chron_ban_list.php.

18. Le GV, Takahashi K, Park EK, et al. Asbestos use and asbestosrelated diseases in Asia: past, present and future. Respirology 2011;16:767-75.

19. Wang JD, Lee LJH, Lin LJ, et al. Deadly dust: asbestos-related diseases, a major occupational disease epidemic in the history of industrialization: OSHlink.org.tw, 2017.

20. Wu TH, Lee LJ, Yuan CT, et al. Prognostic factors and treatment outcomes of malignant pleural mesothelioma in Eastern Asian patients - A Taiwanese study. J Formos Med Assoc 2018.

21. Lee LJH, Takahashi K, Chang YY, et al. Estimating impacts of asbestos-related malignant mesothelioma: quantification of life expectancy lost and lifetime healthcare expenditures in Taiwan. SD L, ed. Asbestos: risk assessment, health implications and impacts on the environment: Nova Science Pub Inc, 2016.

22. Taiwan Cancer Registry. Taiwan Cancer registry introduction 2015. http://www.hpa.gov.tw/EngPages/Detail.aspx?nodeid=1061\&pid= 6071 (accessed 4 Apr 2017).

23. Fritz AG. International classification of diseases for oncology: ICD-O. 3rd edn. Geneva: World Health Organization, 2000.

24. Boyle P, Parkin DM. Cancer registration: principles and methods. Statistical methods for registries. IARC Sci Publ 1991;95:126-58.

25. Taiwan Cancer Registry. Annual reports of Taiwan Cancer Registry. 2017 http://crs.cph.ntu.edu.tw/main.php?Page=A5-t01 (accessed 31 Mar 2017).

26. Rothman KJ, Boice JD. Epidemiologic analysis with a programmable calculator. Bethesda, MD, Washington: U.S. Dept. of Health, Education, and Welfare, Public Health Service for sale by the Supt. of Docs, 1979.

27. Ministry of the Interior. Standards of permissible exposure limits of airborne hazardous substances in workplace. Taiwan Ministry of the Interior, 1981.

28. National Cancer Institute. Cancer cluster. https://www.cancer.gov/ about-cancer/causes-prevention/risk/substances/cancer-clustersfact-sheet (accessed 23 Mar 2017).

29. Mensi C, Riboldi L, De Matteis S, et al. Impact of an asbestos cement factory on mesothelioma incidence: global assessment of effects of occupational, familial, and environmental exposure. Environ Int 2015;74:191-9.

30. Kishimoto T, Ozaki S, Kato K, et al. Malignant pleural mesothelioma in parts of Japan in relationship to asbestos exposure. Ind Health 2004;42:435-9.

31. Corfiati M, Scarselli A, Binazzi A, et al. Epidemiological patterns of asbestos exposure and spatial clusters of incident cases of malignant mesothelioma from the Italian national registry. BMC Cancer 2015:15:286.

32. Mensi C, De Matteis S, Catelan D, et al. Geographical patterns of mesothelioma incidence and asbestos exposure in Lombardy, Italy. Med Lav 2016;107:340-55.

33. Mehlman MA. Dangerous and cancer-causing properties of products and chemicals in the oil-refining and petrochemical industries. Part IX: Asbestos exposure and analysis of exposures. Ann N Y Acad Sci 1991;643:368-89.

34. Gennaro V, Ceppi M, Boffetta P, et al. Pleural mesothelioma and asbestos exposure among Italian oil refinery workers. Scand $J$ Work Environ Health 1994;20:213-5.

35. Miller A. Mesothelioma in household members of asbestos-exposed workers: 32 United States cases since 1990. Am J Ind Med 2005;47:458-62.

36. Fazzo L, De Santis M, Minelli G, et al. Pleural mesothelioma mortality and asbestos exposure mapping in Italy. Am J Ind Med 2012;55:11-24.

37. Chang HY, Chen CR, Wang JD. Risk assessment of lung cancer and mesothelioma in people living near asbestos-related factories in Taiwan. Arch Environ Health 1999;54:194-201.

38. Furuya S, Chimed-Ochir O, Takahashi K, et al. Global asbestos disaster. Int J Environ Res Public Health 2018;15:1000.

39. Update Global Situation on Asbestos. International conference: expedite asia to be free from asbestos hazard global scientific and social evidence. Bangkok, Thailand, 2014.

40. Taiwan EPA. Information for Asbestos hazards in Taiwan (in Chinese). 2016 http://www.epa.gov.tw/mp.asp?mp=abtos (accessed $30 \mathrm{March}$ 2017).

41. Gordon JR, Leigh J. Medicolegal aspects of the third wave of asbestos-related disease in Australia. Med J Aust 2011;195:247-8.

42. Landrigan PJ. The third wave of asbestos disease: exposure to asbestos in place. Public health control. Introduction. Ann N Y Acad Sci 1991;643:xv-xvi. 
43. Ministry of Labour. Recognition guideline for asbestos related mesothelioma in Taiwan. 1st edn, 2011.

44. Goswami E, Craven V, Dahlstrom DL, et al. Domestic asbestos exposure: a review of epidemiologic and exposure data. Int $J$ Environ Res Public Health 2013;10:5629-70.

45. ICOH. Dublin statement on occupational health: new avenues for prevention of occupational cancer and other severe occupational

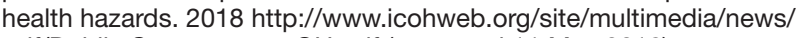
pdf/Dublin Statement on OH.pdf (accessed 11 May 2018).

46. New Zealand. The Management of Asbestos in the Non-Occupational Environment: Guidelines for Public Health Units. 5th ed, 2017.

47. Ministry of the Interior. Demoltion of the buildings: caution for asbestos, potential exposure to asbestos exited in buildings constructed before 2006. https://asbestos.epa.gov.tw/MOI.aspx (accessed 12 May 2018).

48. Taiwan EPA. Asbestos hazards information section. 2018. updated 27 April 2018. Available from https://asbestos.epa.gov.tw/ (accessed 12 May 2018).

49. World Health Organization. Age standardization of rates: a new WHO standard. 2001 http://www.who.int/healthinfo/paper31.pdf (accessed 16 May 2018).

50. Arif Q, Husain AN. Malignant mesothelioma diagnosis. Arch Pathol Lab Med 2015;139:978-80.

51. Hinterberger M, Reineke T, Storz M, et al. D2-40 and calretinin - a tissue microarray analysis of 341 malignant mesotheliomas with emphasis on sarcomatoid differentiation. Mod Pathol 2007;20:248-55.

52. Ascoli V. Pathologic diagnosis of malignant mesothelioma: chronological prospect and advent of recommendations and guidelines. Ann Ist Super Sanita 2015;51:52-9.

53. Zielhuis RL. Public health risks of exposure to asbestos. Report of a Working Group of experts prepared for the Commission of the European Communities, Directorate-General for Social Affairs, Health and Safety Directorate. Headington Hill Hall, Oxford OX3 OBW: Pergamon Press Ltd, 1977.

54. McCaughey WT, Kannerstein M, Churg J. Tumors and pseudotumors of the serous membranes. Washington, D.C: Armed Forces Institute of Pathology, 1985.
55. Battifora H, McCaughey WT. Tumors of the serosal membranes. Washington, D.C: Armed Forces Institute of Pathology, 1995.

56. Wu MZ, Lee LJH. 2018. Personal communication with a senior pathologist Dr. Mu-Zon Wu, National Taiwan University Hospital.

57. World Health Organization, International Agency for Research on Cancer. Pathology and genetics of tumours of the lung, pleura, thymus and heart. 3rd edn. Lyon: IARC Press, 2004.

58. Langård S, Lee LJ. Methods to recognize work-related cancer in workplaces, the general population, and by experts in the clinic, a Norwegian experience. J Occup Med Toxicol 2011;6:24.

59. Sen D. Working with asbestos and the possible health risks. Occup Med 2015;65:6-14.

60. Jung SH, Kim HR, Koh SB, et al. A decade of malignant mesothelioma surveillance in Korea. Am $\mathrm{J}$ Ind Med 2012:55:869-75.

61. Safe Work Australia. Hazardous chemicals requiring health monitoring. http://www.safeworkaustralia.gov.au/sites/swa/about/ publications/pages/hazardous-chemicals-requiring-health-monitoring (accessed 31 Mar 2017).

62. Hsiao FJ, Cheng Y, Lee LJH. Occupational health examination for asbestos-exposed workers and surveillance system for malignant mesothelioma: International experiences and conditions of Taiwan. Taiwan Journal of Public Health 2017;36:187-96.

63. Collegium R. Collegium Ramazzini. The 18th Collegium Ramazzini statement: the global health dimensions of asbestos and asbestosrelated diseases. Scand J Work Environ Health 2016:42:86-90.

64. Wolff H, Vehmas T, Oksa P, et al. Asbestos, asbestosis, and cancer, the Helsinki criteria for diagnosis and attribution 2014: recommendations. Scand J Work Environ Health 2015;41:5-15.

65. Ollier M, Chamoux A, Naughton G, et al. Chest CT scan screening for lung cancer in asbestos occupational exposure: a systematic review and meta-analysis. Chest 2014;145:1339-46.

66. Kato K, Gemba K, Ashizawa K, et al. Low-dose chest computed tomography screening of subjects exposed to asbestos. Eur J Radiol 2018;101:124-8.

67. Yang SC, Lai WW, Lin CC, et al. Cost-effectiveness of implementing computed tomography screening for lung cancer in Taiwan. Lung Cancer 2017;108:183-91. 